\title{
Ultrasound-Guided Prostate Biopsy
}

National Cancer Institute

\section{Source}

National Cancer Institute. Ultrasound-Guided Prostate Biopsy. NCI Thesaurus. Code C116510.

A diagnostic procedure that uses an ultrasound image to guide the placement of a biopsy needle into the prostate to obtain a tissue sample. 